\title{
An annoyance from an anomalous OS
}

\author{
Sandesh Madi, ${ }^{1}$ Vivek Pandey, ${ }^{1}$ Vishnu Senthil, ${ }^{1}$ Kiran Acharya ${ }^{2}$
}

${ }^{1}$ Department of Orthopaedics, Kasturba Medical College Manipal, Manipal, Karnataka, India

${ }^{2}$ Department of Orthopaedics, Manipal University, Manipal, Karnataka, India

\section{Correspondence to} Dr Sandesh Madi, sandesh.madi@gmail.com

Accepted 19 February 2016

\section{DESCRIPTION}

A 32-year-old man, a farmer, presented with chronic pain in his left foot of 9 years duration. There was no history of trauma. Pain was typically aggravated by walking in the fields (uneven ground) or after prolonged standing. Several orthopaedists had treated this condition as an ankle sprain and plantar fasciitis for the past 9 years. However, the symptoms persisted. Clinical examination revealed a normal gait and normally arched left foot. No swelling was noted anywhere in the foot and ankle. Tenderness was noted over the lateral border of the foot, close to the calcaneocuboid joint. Eversion of the foot was characteristically painful and limited.

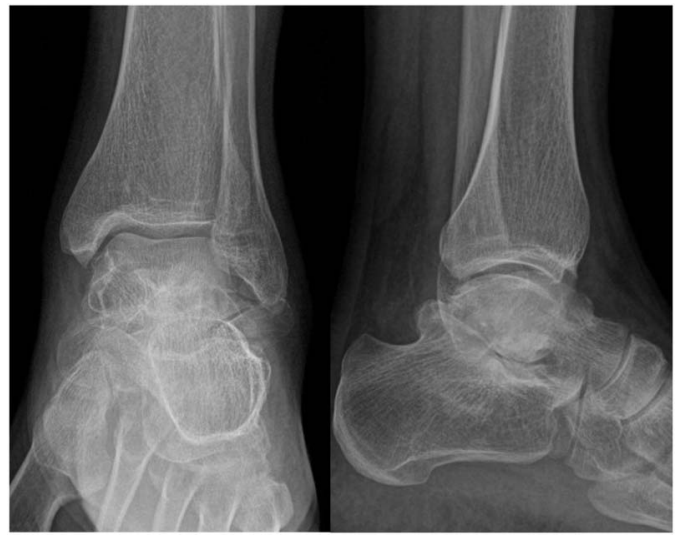

Figure 1 Anteroposterior and lateral views of the left ankle; (A) bony prominence wedged between the lateral portion of the talus and calcaneus, distal to the tip of the fibula, can be appreciated.
A bony prominence was noted distal to the fibula on plain X-rays (anteroposterior and lateral views) of the ankle (figure 1). MRI (1.5 T) study of the ankle observed a well-corticated bone lateral to the tip of the lateral malleolus articulating with the subtalar joint, suggestive of an accessory tarsal bone (figure 2).

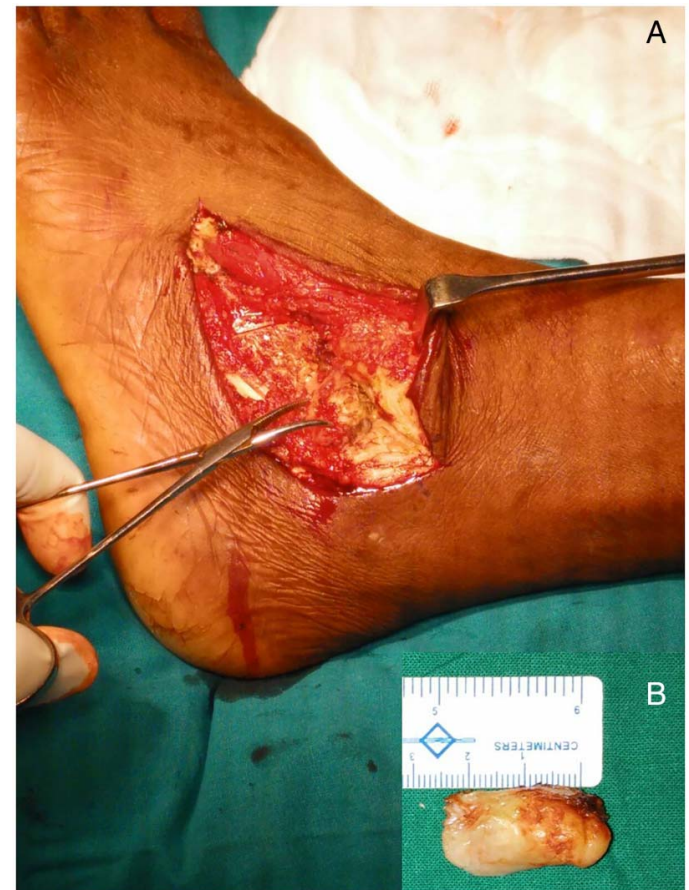

Figure 3 Intra-articular photograph of the surgical excision of the anomalous ossicle. (Inlet (B): a well corticated and nodular ossicle).
To cite: Madi S, Pandey $V$ Senthil V, et al. BMJ Case Rep Published online: [please include Day Month Year] doi:10.1136/bcr-2016214540

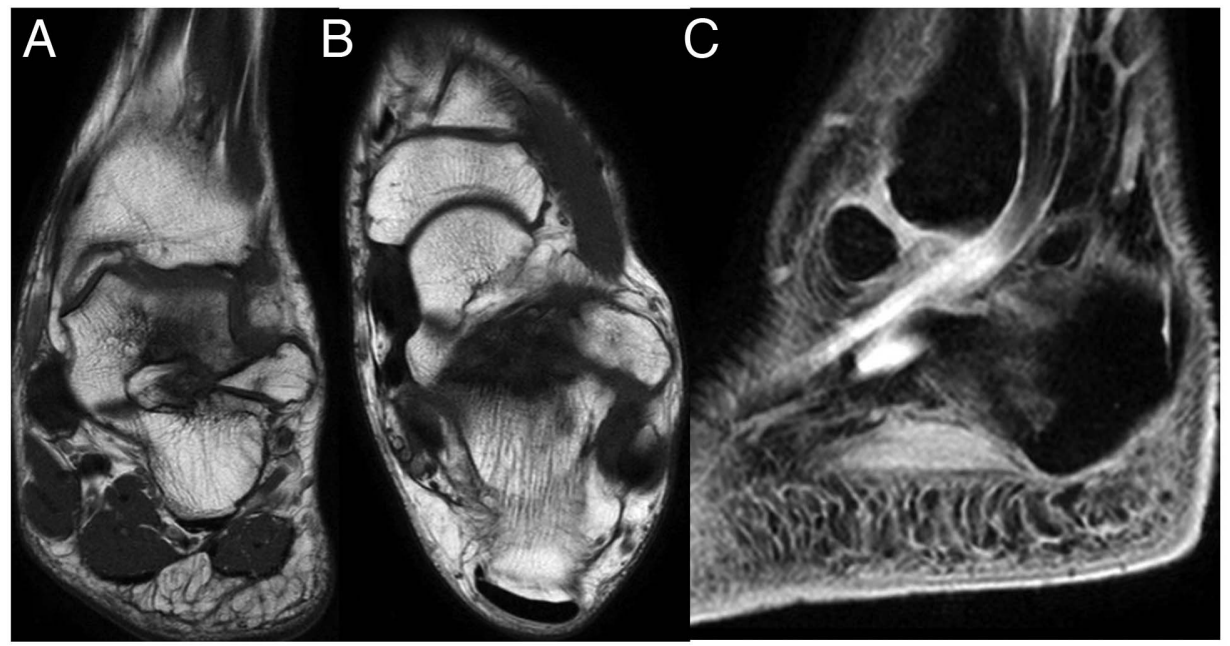

Figure 2 MRI (1.5 T) of the left ankle: (A) coronal view (T2 weighted); (B) axial view (T1 weighted); (C) sagittal view (water saturation) showing a well corticated osseous T1 and T2 hypointense structure with cortex, and T1 and T2 hyperintense medulla. 


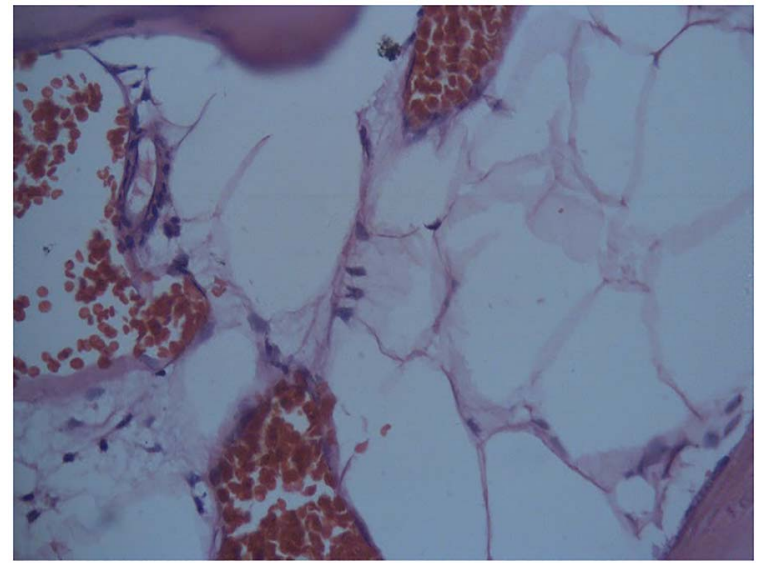

Figure 4 Low power microscopy showing normal bony trabecular septations along with fat marrow and blood vessels. (H\&E stain).

The bony prominence (measuring $2.5 \times 1.5 \times 1 \mathrm{cms}$ ) was surgically excised (figure 3 ). The histopathological assessment revealed it to be composed of the normal trabecular bone pattern (figure 4). Postoperatively, the patient was mobilised under a graduated weight-bearing rehabilitation programme. At 23 months follow-up, his American Foot and Ankle Score was 98. A comprehensive literature search was carried out, and this case was finally diagnosed as os talus secundarius.

Os talus secundarius is a rare accessory ossicle found near the lateral aspect of the talus, distal to the tip of the lateral malleolus. There are only six articles about this ossicle in the literature (since 1953), in which four cases were reported to be symptomatic. ${ }^{1}$ The index case, a farmer, was involved in hard labour, working mostly on uneven ground. Despite pain, the patient continued with his activities, which could have resulted in the ossicle enlargement and eventual overt symptoms. This accessory ossicle articulates with the talus either by a synchondrosis or a synostosis, and can form a set of anomalous articulations with the lateral superior surface of the calcaneus and the lateral malleolus. ${ }^{2}$ Differential diagnosis includes Os subfibulare, Os peroneum, subtalar synovial chondromatosis and traumatic or degenerative osteochondral fragments. MRI is the most helpful in defining the relationship of the ossicle with the talus and the calcaneus besides investigating for other pathological conditions such as fractures, infections and osteoarthritis. Surgical excision of the ossicle in the index case ensured prompt symptomatic relief and is the current standard of treatment. ${ }^{1}$

\section{Learning points}

- Os talus secundarius is an uncommon accessory ossicle of the foot and has been rarely reported to be symptomatic.

- This condition becomes clinically symptomatic when the ossicle interposes between the talus and the calcaneus, affecting the movements at the subtalar joint, resulting in pain and restriction.

- Awareness about this anatomical variance among radiologists and surgeons can prevent delay in the diagnosis and hasten appropriate management.

- Surgical excision of the 'symptomatic' ossicle results in prompt relief and is the recommended treatment.

Competing interests None declared.

Patient consent Obtained.

Provenance and peer review Not commissioned; externally peer reviewed.

\section{REFERENCES}

1 Oliveira F, Serrano P, Faísca J, et al. Symptomatic os talus secundarius: a case report. Eur Orthop Traumatol 2012;3:261-2.

2 Viana SL, Fernandes JL, Mendonca JL, et al. Painful os talus secundarius: a case report and imaging findings. Foot Ankle Int 2007;28:624-5.

Copyright 2016 BMJ Publishing Group. All rights reserved. For permission to reuse any of this content visit

http://group.bmj.com/group/rights-licensing/permissions.

BMJ Case Report Fellows may re-use this article for personal use and teaching without any further permission.

Become a Fellow of BMJ Case Reports today and you can:

- Submit as many cases as you like

- Enjoy fast sympathetic peer review and rapid publication of accepted articles

- Access all the published articles

- Re-use any of the published material for personal use and teaching without further permission

For information on Institutional Fellowships contact consortiasales@bmjgroup.com

Visit casereports.bmj.com for more articles like this and to become a Fellow 